\title{
Breakfast consumption and nutrient intakes in 4-18-year-olds: UK National Diet and Nutrition Survey Rolling Programme (2008-2012)
}

\author{
Janine D. Coulthard ${ }^{1}$, Luigi Palla ${ }^{2}$ and Gerda K. Pot ${ }^{1,3 *}$ \\ ${ }^{1}$ Diabetes and Nutritional Sciences Division, King's College London, Faculty of Life Sciences and Medicine, Franklin-Wilkins \\ Building, 150 Stamford Street, London SE1 9NH, UK \\ ${ }^{2}$ Department of Medical Statistics, London School of Hygiene and Tropical Medicine, Faculty of Epidemiology and Population \\ Health, Keppel St, London WC1E 7HT, UK \\ ${ }^{3}$ Section of Health and Life, Faculty of Earth and Life Sciences, Vrije University Amsterdam, de Boelelaan 1085,1081 HV \\ Amsterdam, The Netherlands
}

(Submitted 3 March 2017 - Final revision received 26 May 2017 - Accepted 8 June 2017 - First published online 17 August 2017)

\begin{abstract}
Although breakfast consumption is widely considered to be an important component of a healthy lifestyle, few UK studies have examined differences in nutrient intakes between breakfast consumers and breakfast skippers among children and adolescents. We investigated associations between breakfast skipping in 4-18-year-olds and their nutrient intakes using data from the UK's National Diet and Nutrition Survey Rolling Programme. Dietary data were derived from 4-d estimated food diaries of 802 children aged 4-10 years and 884 children aged 11-18 years (1686 in total). Daily nutrient intakes of children with different breakfast habits were compared by one-way ANCOVA adjusting for relevant covariates (sex, age, ethnicity, equivalised household income and BMI). Within-person analysis was carried out on children with an irregular breakfast habit ( $n$ 879) comparing nutrient intakes on breakfast days with those on non-breakfast days using repeated measures ANCOVA. We observed that the overall nutritional profile of the children in terms of fibre and micronutrient intake was superior in frequent breakfast consumers (micronutrients: folate, $\mathrm{Ca}, \mathrm{Fe}$ and I $(P<0 \cdot 01))$ and, for the 4-10 years age group, on breakfast days (micronutrients: folate, vitamin $\mathrm{C}, \mathrm{Ca}$ and I $(P<0 \cdot 01)$ ). Also, significantly higher proportions of breakfast-consuming children met their reference nutrient intakes of folate, vitamin $\mathrm{C}$, Ca, Fe and I compared with breakfast skippers $\left(\chi^{2}\right.$ analysis, $\left.P<0 \cdot 001\right)$. Our study adds to the body of data linking breakfast consumption with higher quality dietary intake in school-age children, supporting the promotion of breakfast as an important element of a healthy dietary pattern in children.
\end{abstract}

Key words: Children: Dietary patterns: Breakfast: Nutrient intakes: National Diet and Nutrition Survey Rolling Programme

Breakfast is widely considered to be an important component of a healthy lifestyle for both adults and children. Its consumption is promoted by the UK Government's ChangefLife public health campaign in England ${ }^{(1)}$. One of the suggested benefits of breakfast for children and adolescents is that eating breakfast regularly protects against overweight and obesity. To date, evidence for this consists largely of epidemiological studies ${ }^{(2-9)}$ and intervention studies have so far failed to demonstrate a causal relationship between breakfast habit and adiposity ${ }^{(10-13)}$. Another proposed benefit of breakfast consumption in children and adolescents is that it improves overall nutrient intakes ${ }^{(2)}$.

Previous studies have been carried out into variations in nutritional intakes dependent on child breakfast habits, but many of these focus on consumption of a specific type of breakfast, for example breakfast cereal ${ }^{(14-16)}$ or a 'good-quality' breakfast ${ }^{(17)}$. Some have examined overall differences in nutritional profile between children who eat breakfast and those that do not, including recent studies involving North American, Mexican and Australian populations ${ }^{(18-22)}$, and have reported that breakfast consumption compared with breakfast skipping was associated with improved nutrient intakes ${ }^{(18,20-30)}$. However, the authors are not aware of any recent studies of UK or other European children examining differences in nutrient intakes between breakfast consumers and breakfast skippers. Therefore, our main aim in this study was to investigate associations between breakfast skipping in 4-18-year-olds and their nutrient intakes using data from the UK's National Diet and Nutrition Survey Rolling Programme (NDNS RP). We compared daily nutrient intakes between children with different breakfast habits and also carried out a within-person analysis, comparing intakes of children on breakfast days with their intakes on non-breakfast days. This latter approach was adopted in order to minimise the impact of residual confounding inherent in cross-sectional studies.

Abbreviations: EAR, estimated average requirement; LRNI, lower reference nutrient intake; NDNS RP, National Diet and Nutrition Survey Rolling Programme; NMES, non-milk extrinsic sugars.

* Corresponding author: G. K. Pot, email Gerda.Pot@kcl.ac.uk 
Many epidemiological studies comparing the characteristics of individuals with different breakfast habits ask participants (or their parents) how frequently they (or their children) consume breakfast, but do not include a definition of this meal ${ }^{(4,27,31,32)}$. Where breakfast is defined, this definition varies widely ${ }^{(2,33,34)}$. Some studies classify any energy intake within a specified time period as breakfast ${ }^{(19,21)}$, others include only solid foods and not beverages in the definition, regardless of the energy content of the latter ${ }^{(34)}$. We employed an objective definition of breakfast, based on a minimum energy intake within a specified time period. We hypothesised that intakes of micronutrients of public health interest, which have a key role in children's healthy development and growth, may be particularly affected by breakfast skipping, as many breakfast items consumed widely by UK children, such as breakfast cereals, fruit juice and dairy products, are important sources of micronutrients for this age group ${ }^{(35)}$.

\section{Methods}

\section{Population}

The data analysed in this study were collected between 2008 and 2012 as part of the NDNS RP ${ }^{(36)}$. Each year the NDNS RP gathers dietary and nutritional data from approximately 1000 randomly sampled individuals living in private UK households, comprising equal numbers of adults (aged 19 years and over) and children (aged 1.5-18 years) ${ }^{(35)}$. These individuals are sampled using The Royal Mail's Postcode Address File, comprising all UK addresses, to randomly select addresses. Where there is more than one household at a selected address, one of these households is randomly selected. At each selected household either one adult and one child (if present) are selected, or one child, resulting in roughly equal numbers of adults and children in the final sample. Chapter 2 of the report on the NDNS RP results from years $1-4$ (combined) ${ }^{(35)}$ gives fuller details of its methodology. This study focused on the subpopulation of children in the NDNS RP 2008-2012 sample aged 4-18 years, consisting of 802 children aged 4-10 years and 884 children aged 11-18 years (1686 in total). Ethics approval for the NDNS RP was obtained from Oxfordshire A Research Ethics Committee ${ }^{(35)}$

\section{Dietary assessment}

Each survey participant was visited in their home by a survey interviewer, who placed a 4-d estimated (unweighed) food diary (with written instructions) to be completed on 4 consecutive days by the participant, or their parent for those aged 11 years and under ${ }^{(37,38)}$. Follow-up checks were made by the interviewer to optimise completeness of record keeping in the diary $^{(35)}$. Within the sample analysed for years 2008 to 2012 of the NDNS RP 1686 children aged 4-18 years completed at least 3 diary days (98.2\% of these completed the full 4 diary days). Home visits were carried out continuously throughout each year, from February 2008 to August 2012, thus allowing for seasonal variations in $\operatorname{diet}^{(39)}$.

The diary entries were then recorded and analysed by a dietary assessment system using food composition data from the Department of Health's NDNS Nutrient Databank to estimate energy and nutrient intakes ${ }^{(37)}$. The NDNS Nutrient Databank is based on data from McCance and Widdowson's The Composition of Foods series ${ }^{(37,40)}$. Non-milk extrinsic sugars (NMES) were defined as comprising all free sugars (added monosaccharides and disaccharides, together with naturally occurring sugars in honey, syrups and fruit juices) and $50 \%$ of fruit sugars from stewed, dried or canned fruit ${ }^{(41)}$. Dietary fibre intakes were of NSP, defined by the Englyst method ${ }^{(42)}$. Mean daily energy intakes were expressed as a percentage of the estimated average requirement (EAR) for each child, as specified by the Scientific Advisory Committee on Nutrition ${ }^{(43)}$. Mean daily intakes of the micronutrients folate, vitamin C, Ca, Fe and I were compared with dietary reference values (DRV) (reference nutrient intakes (RNI) and lower reference nutrient intakes (LRNI)) for each child, as set by the Committee on Medical Aspects of Food Policy ${ }^{(44)}$. The results of the above analysis of the diary entries form part of the published core sample data for the NDNS RP 2008-2012 ${ }^{(36)}$ and were further analysed in this study as described below.

For each day the food diary entries had been split into seven different time periods: 06.00-08.59, 09.00-11.59, 12.00-13.59, 14.00-16.49, 17.00-19.59, 20.00-21.59 and 22.00-05.59 hours. Microsoft Excel for Mac 2011 (version 14.4.6) and IBM SPSS Statistics (version 23) were used to calculate the total energy intake for each diary day between 06.00 and 08.59 hours and identify those days on which at least $418 \mathrm{~kJ}$ ( $100 \mathrm{kcal})$ were consumed between 06.00 and 08.59 hours (breakfast days) and those on which $<418 \mathrm{~kJ}$ ( $<100 \mathrm{kcal}$ ) were consumed (nonbreakfast days). The threshold of $418 \mathrm{~kJ}$ (100 kcal) was chosen to allow for consumption of a milky drink which was not considered sufficient to be classed as breakfast ${ }^{(45)}$. Using these data, the children were split into three categories: those consuming breakfast every diary day, those consuming breakfast on at least one but not all diary days, and those not consuming breakfast on any diary day. A subset of the group of children with an irregular breakfast habit, that is who consumed breakfast on at least one but not all diary days, was created by eliminating all diary days that comprised a Saturday or a Sunday and then identifying all children who still had an irregular breakfast habit based on weekday diary days alone. This was to correct for a possible shift to later breakfast time and/or a different pattern in nutrient intakes at the weekend. For each child with an irregular breakfast habit mean daily nutrient intakes for breakfast days and non-breakfast days, respectively, were calculated.

The nutrients selected for analysis in this study were the macronutrients protein, fat and carbohydrate plus a selection of other nutrients linked with an unhealthy (NMES and $\mathrm{Na}$ ) or a healthy diet (dietary fibre). We also analysed intakes of a selection of micronutrients that Public Health England has identified as being of particular interest to public health, namely: folate, $\mathrm{Fe}$, vitamin $\mathrm{C}$ and $\mathrm{Ca}^{(35)}$. To this list we added $\mathrm{I}$ : there is some evidence of I deficiency in UK adolescent girls giving rise to public health concerns due to its vital role in fetal neurodevelopment ${ }^{(46)}$. The mean daily nutrient intake values were expressed as a percentage of total energy intake for protein, fat, carbohydrate and NMES and as mean intakes per 
$4184 \mathrm{~kJ}(1000 \mathrm{kcal})$ of energy intake for the remaining nutrients. This was to allow for possible differences in daily energy intakes between breakfast and non-breakfast eaters

\section{Other measures}

During the home visit, the interviewer measured the weight and height of the participant so that their BMI could be calculated (weight in kilograms divided by the square of height in metres) ${ }^{(35)}$. The calculated BMI and the British 1990 growth reference (UK90) charts ${ }^{(47)}$ were used to categorise the children as normal weight, overweight (85th centile cut-off) or obese (95th centile cut-off). The interviewer also conducted a computer-assisted personal interview to collect further data on the individual and their household, including age, ethnicity (five main categories: white, mixed, black or black British, Asian or Asian British, and other), whether the individual was currently dieting to lose weight (a 'yes' or 'no' response, years 3 and 4 of the NDNS RP, for individuals 11 years and older) and household income (choice of thirteen income bands, ranging from under $£ 5000$ to $£ 100000$ or more $)^{(48)}$.

\section{Statistical analysis}

The energy-adjusted daily nutrient intake, equivalised household income (equivalised for different household sizes and composition using the McClements equivalence scale $\left.{ }^{(35)}\right)$ and BMI variables were checked for normality by inspecting frequency distribution histograms and skew and kurtosis values and transformed as necessary. The differences between the children grouped by three categories of breakfast habit (consumption of breakfast on every, some or no diary days) with respect to sex, age, ethnicity, weight status and equivalised household income were assessed by $\chi^{2}$ analysis and ANOVA. $\chi^{2}$ analysis was carried out on the dieting variable and used to examine the proportions of children meeting the RNI and LRNI for daily intakes of the selected micronutrients. $\chi^{2}$ analysis was also used to compare the characteristics of children with missing BMI and/or income data to assess whether the relatively high incidence of missing data ( $n$ 270, 16\% of sample) might affect the results adjusted for these variables.

Daily nutrient intakes for the three groups of children with different breakfast habits were compared by one-way ANOVA and then ANCOVA, with adjustments made for the following covariates: sex, age, ethnicity, equivalised household income and BMI. Energy intake for this analysis was expressed as a proportion of EAR, to allow for variations in energy intake with age and sex. To investigate the potential effect of underor over-reporting of dietary intakes a sensitivity analysis was carried out, rerunning the $\chi^{2}$ analysis of children meeting the DRV and the ANCOVA analysis of energy intake after eliminating those children with energy intake as a proportion of EAR more than $2 \mathrm{sD}$ from $100 \%$ (as described by McCrory et $\left.a l{ }^{(49)}\right)$. This was not considered necessary for the nutrient intakes, as these were all expressed as a proportion of energy intake. Due to inequality of variance (assessed using Levene's test) for three of the nutrient variables: protein, NMES and $\mathrm{Na}$, which can lead to an increase in type 1 error rate $^{(50)}$, the ANOVA and ANCOVA analyses for these variables were carried out after equalising the numbers in the three groups of children by random sampling, to create three equal groups of 245 cases each (for large sample sizes and modest levels of variance heterogeneity ANOVA is generally robust to inequality of variances if group sizes are equal ${ }^{(50)}$ ).

Within-person analysis was carried out on the children with an irregular breakfast habit ( $n$ 879), comparing their mean energy-adjusted nutrient intakes for days on which they had consumed breakfast with those for days on which they had not. It was assumed that any degree of mis-reporting of dietary intakes by an individual would be similar across the diary days and would therefore not have a significant effect on the withinperson analysis. Paired sample $t$ tests were conducted, followed by repeated measures ANOVA, the latter adjusted for the covariates sex, age, BMI, ethnicity and equivalised household income. These tests were also carried out on the sample split into two age groups: 4-10 years ( $n$ 384) and $11-18$ years ( $n$ 495) and on the subset of 4-18-year-olds with an irregular breakfast habit after removal of weekend diary days. Due to collinearity of nutrient variables, for all the tests carried out a $P$ value of $<0.01$ was considered as statistically significant to allow for multiple testing, rather than using the potentially overly conservative Bonferroni method of adjustment ${ }^{(51)}$. We did not apply the weighting as provided with the NDNS 20082012 RP data set, as the calibration weights may not reflect the characteristics of the subsample of children that we analysed, which may not be representative of the UK population.

\section{Results}

\section{Description of population}

The characteristics of the children, split by breakfast habit, are set out in Table 1 . There was a significant variation in breakfast habit between girls and boys $(P=0 \cdot 001)$, with $19.9 \%$ of girls skipping breakfast every diary day compared with $14.5 \%$ of boys. At $6.5 \%$, the proportion of the 4-10-year-olds skipping breakfast every diary day was less than a quarter of the proportion of 11-18-year-olds $(26 \cdot 8 \%)$, and the proportion in the younger age group consuming breakfast every day was $45.6 \%$, more than twice that of the older age group $(P<0 \cdot 001)$. Mean equivalised household income varied significantly with breakfast habit $(P=0.001)$, with a mean household income of £28194 (SD £18349) for those children consuming breakfast every diary day compared with a mean household income of £23587 (SD £16374) for those children skipping breakfast every diary day. There was no significant difference in breakfast habits based on ethnicity or weight status. Data on whether or not the children were dieting during the diary period were only available for 11-18-year-olds in years 3 and 4 of the NDNS RP. A significantly higher percentage of girls were dieting than boys $(10.7 v \cdot 3.4 \%, P=0.003, n 430)$, but no significant variation in breakfast habit with dieting behaviour was observed for the children as a whole $(P=0.456)$, or for the girls alone $(P=0.419, n 224)$ (the $\chi^{2}$ analysis was invalid for the boys as more than $20 \%$ of the expected cell values were $<5$ ). There were no significant differences found in sex $(P=0.457)$, age group ( $P=0.470)$ or breakfast habit $(P=0.844)$ for children with missing $\mathrm{BMI}$ and/or income data compared with those with complete data. 
Table 1. Characteristics of children by breakfast eating habit showing sex, age, ethnicity, weight status and household income (n 1686)

(Numbers and percentages; mean values and standard deviations)

\begin{tabular}{|c|c|c|c|c|c|c|c|}
\hline & \multicolumn{2}{|c|}{ Breakfast no diary days } & \multicolumn{2}{|c|}{$\begin{array}{c}\text { Breakfast on at least one but not all } \\
\text { diary days }\end{array}$} & \multicolumn{2}{|c|}{ Breakfast every diary day } & \multirow[b]{2}{*}{$P^{*}$} \\
\hline & $n$ & $\%$ & $n$ & $\%$ & $n$ & $\%$ & \\
\hline Total & 289 & $17 \cdot 1$ & 879 & $52 \cdot 1$ & 518 & $30 \cdot 7$ & \\
\hline \multicolumn{8}{|l|}{ Sex } \\
\hline Male & 124 & 14.5 & 443 & $51 \cdot 6$ & 291 & 33.9 & \multirow[t]{2}{*}{$0.001 \dagger$} \\
\hline Female & 165 & 19.9 & 436 & $52 \cdot 7$ & 227 & $27 \cdot 4$ & \\
\hline \multicolumn{8}{|l|}{ Age (years) } \\
\hline $4-10$ & 52 & 6.5 & 384 & 47.9 & 366 & $45 \cdot 6$ & \multirow[t]{2}{*}{$<0.001 \dagger$} \\
\hline $11-18$ & 237 & $26 \cdot 8$ & 495 & $56 \cdot 0$ & 152 & $17 \cdot 2$ & \\
\hline \multicolumn{8}{|l|}{ Ethnicity } \\
\hline White & 240 & $16 \cdot 5$ & 757 & $52 \cdot 1$ & 455 & $31 \cdot 3$ & \multirow[t]{2}{*}{0.168} \\
\hline Non-white & 49 & $20 \cdot 9$ & 122 & $52 \cdot 1$ & 63 & $26 \cdot 9$ & \\
\hline \multicolumn{8}{|l|}{ Weight status $\ddagger$} \\
\hline Normal & 195 & $17 \cdot 7$ & 553 & $50 \cdot 2$ & 353 & $32 \cdot 1$ & \multirow[t]{3}{*}{0.258} \\
\hline Overweight & 33 & 14.9 & 120 & $54 \cdot 3$ & 68 & $30 \cdot 8$ & \\
\hline \multirow[t]{2}{*}{ Obese } & 52 & $17 \cdot 5$ & 167 & $56 \cdot 2$ & 78 & $26 \cdot 3$ & \\
\hline & Mean & SD & Mean & SD & Mean & SD & $P \S$ \\
\hline Household income $(£) \|$ & 23587 & 16374 & 25108 & 16998 & 28194 & 18349 & $0.001 \dagger$ \\
\hline
\end{tabular}

\section{Breakfast habits and micronutrient Dietary Reference Values}

Significant increases $(P<0.001)$ were noted in the proportion of children meeting their RNI for each of the micronutrients folate, vitamin $\mathrm{C}, \mathrm{Ca}, \mathrm{Fe}$ and I as breakfast frequency increased (Table 2). The same trend was observed in the proportion of children meeting the LRNI for folate, $\mathrm{Ca}, \mathrm{Fe}$ and I $(P<0.001)$. No children who consumed breakfast daily had a folate intake below their LRNI, compared with $7.3 \%$ of those who did not eat breakfast on any diary day. The proportions of children not meeting their LRNI of $\mathrm{Ca}, \mathrm{Fe}$ and I in the daily breakfast group were $2 \cdot 9,4.4$ and $3 \cdot 3 \%$, respectively, compared with $19 \cdot 0,31 \cdot 5$ and $21.5 \%$, respectively, in the breakfast skipping group. Similar results were obtained for the sensitivity analysis including only plausible reporters of energy intake ( $n$ 1505) (invalid LRNI $\chi^{2}$ results for folate and vitamin $\mathrm{C}$ as more than $20 \%$ of cells had expected count of $<5$ ).

\section{Breakfast habits and nutrient intakes}

After adjustment for covariates, we observed significant increases in mean intakes of energy (as a percentage of EAR) $(P=0.009)$ and carbohydrates (as a percentage of energy) $(P=0.01)$ and decreases in mean intakes of fat (as a percentage of energy) $(P=0.005)$, with increasing number of breakfast days (Table 3). However, after eliminating implausible reporters of energy intakes (energy intake as a percentage of EAR more than two sD from $100 \%$ (i.e. outside the range 54-146\%)), the increases in energy intakes became non-significant $(P=0.088, n$ 1271). The percentage of plausible reporters in the sample was $89 \%$, with a significantly higher proportion of plausible reporters within the 4-10-year-olds than 11-18-yearolds (97v. 83\%, $P<0.001)$.

In the ANCOVA analysis we observed no statistically significant variations in intakes of protein, NMES, vitamin C or $\mathrm{Na}$, but energy-adjusted intakes of fibre, folate, $\mathrm{Ca}, \mathrm{Fe}$ and I all increased significantly with increasing frequency of breakfast consumption $(P<0 \cdot 001)$.

\section{Within-person comparison of nutrient intakes on breakfast} days v. non-breakfast days

For 4-18-year-olds, after adjustment for covariates, we observed significantly higher mean intakes of energy, carbohydrate, folate, $\mathrm{Ca}$ and I and significantly lower mean intakes of protein and $\mathrm{Na}$ for days on which breakfast was consumed compared with days on which it was not eaten (Table 4(a)). The mean energy intake for days on which breakfast was consumed was $364 \mathrm{~kJ}$ ( $87 \mathrm{kcal}$ ) higher than for days on which it was not consumed (95\% CI 218, $506 \mathrm{~kJ}(52,121 \mathrm{kcal}) ; P<0.001)$. No significant differences were observed when comparing breakfast with non-breakfast days for mean intakes of fat, NMES, fibre, vitamin $\mathrm{C}$ or Fe.

For 4-10-year-olds there was no significant difference between mean energy intake on days on which breakfast was eaten and mean intake on non-breakfast days (Table 4(b)). In comparison, in the older age group (11-18-year-olds), after adjustment for covariates, energy intake was significantly higher on breakfast days (494 (95 \% CI 276, 707) kJ (118 (95 \% CI 66, 169) kcal); $P<0.001)$ (Table $4(\mathrm{c})$ ). For both age groups carbohydrate intake was significantly higher on breakfast days compared with non-breakfast days. There was a significant decrease in protein intake on 
breakfast days compared with non-breakfast days for the older but not the younger age group. For 4-10-year-olds mean energyadjusted intakes of fibre, folate, vitamin $\mathrm{C}$, Ca and I were

Table 2. Comparison of number and percentage of children below reference nutrient intakes (RNI) (as set by Committee on Medical Aspects of Food Policy (COMA)) and lower reference nutrient intakes (LRNI) (as set by COMA) for folate, vitamin $\mathrm{C}$, calcium, iron and iodine depending on breakfast habit* $(n$ 1686) (Numbers and percentages)

\begin{tabular}{|c|c|c|c|c|c|c|c|}
\hline & \multirow[b]{2}{*}{ Meeting RNI/LRNI } & \multicolumn{2}{|c|}{$\begin{array}{c}\text { Breakfast } \\
\text { no diary } \\
\text { days }\end{array}$} & \multicolumn{2}{|c|}{$\begin{array}{l}\text { Breakfast on at } \\
\text { least one but not } \\
\text { all diary days }\end{array}$} & \multicolumn{2}{|c|}{$\begin{array}{c}\text { Breakfast } \\
\text { every diary } \\
\text { day }\end{array}$} \\
\hline & & $n$ & $\%$ & $n$ & $\%$ & $n$ & $\%$ \\
\hline \multicolumn{8}{|l|}{ Folate } \\
\hline \multirow{2}{*}{$\mathrm{RNI}$} & Yes & 125 & 43.3 & 588 & 66.9 & 426 & $82 \cdot 2$ \\
\hline & No & 164 & $56 \cdot 7$ & 291 & 33.1 & 92 & $17 \cdot 8$ \\
\hline \multirow{2}{*}{ LRNI } & Yes & 268 & 92.7 & 858 & 97.6 & 518 & $100 \cdot 0$ \\
\hline & No & 21 & 7.3 & 21 & $2 \cdot 4$ & 0 & 0.0 \\
\hline \multicolumn{8}{|c|}{ Vitamin C } \\
\hline \multirow[t]{2}{*}{ RNI } & Yes & 213 & 73.7 & 762 & $86 \cdot 7$ & 470 & $90 \cdot 7$ \\
\hline & No & 76 & $26 \cdot 3$ & 117 & 13.3 & 48 & $9 \cdot 3$ \\
\hline \multirow[t]{2}{*}{ LRNI } & Yes & 284 & $98 \cdot 3$ & 876 & 99.7 & 517 & 99.8 \\
\hline & No & 5 & 1.7 & 3 & 0.3 & 1 & 0.2 \\
\hline \multicolumn{8}{|l|}{$\mathrm{Ca}$} \\
\hline \multirow[t]{2}{*}{$\mathrm{RNI}$} & Yes & 92 & 31.8 & 470 & 53.5 & 392 & $75 \cdot 7$ \\
\hline & No & 197 & 68.2 & 409 & 46.5 & 126 & $24 \cdot 3$ \\
\hline \multirow[t]{2}{*}{ LRNI } & Yes & 234 & 81.0 & 819 & $93 \cdot 2$ & 503 & $97 \cdot 1$ \\
\hline & No & 55 & $19 \cdot 0$ & 60 & $6 \cdot 8$ & 15 & $2 \cdot 9$ \\
\hline \multicolumn{8}{|l|}{$\mathrm{Fe}$} \\
\hline \multirow[t]{2}{*}{ RNI } & Yes & 56 & $19 \cdot 4$ & 353 & $40 \cdot 2$ & 303 & 58.5 \\
\hline & No & 233 & 80.6 & 526 & 59.8 & 215 & 41.5 \\
\hline \multirow[t]{2}{*}{ LRNI } & Yes & 198 & 68.5 & 751 & 85.4 & 495 & 95.6 \\
\hline & No & 91 & 31.5 & 128 & $14 \cdot 6$ & 23 & 4.4 \\
\hline \multicolumn{8}{|c|}{ 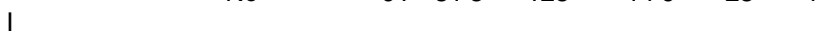 } \\
\hline \multirow[t]{2}{*}{$\mathrm{RNI}$} & Yes & 90 & $31 \cdot 1$ & 400 & 45.5 & 332 & $64 \cdot 1$ \\
\hline & No & 199 & 68.9 & 479 & 54.5 & 186 & 35.9 \\
\hline \multirow{2}{*}{ LRNI } & Yes & 227 & 78.5 & 793 & 90.2 & 501 & 96.7 \\
\hline & No & 62 & 21.5 & 86 & 9.8 & 17 & 3.3 \\
\hline
\end{tabular}

* $P$ values for $X^{2}$ analysis all $<0.001$, except for vitamin $C$ LRNI where results invalid as $50 \%$ of cells had expected count $<5$. significantly higher on days on which breakfast was eaten, but for 11-18-year-olds out of these five nutrients a significant increase was only observed for $\mathrm{Ca}$ intakes. Whereas for the 4-10 years age group there was no significant difference in mean $\mathrm{Na}$ intakes comparing breakfast with non-breakfast days, Na intake was significantly lower for the 11-18 years age group on breakfast days.

For 4-18-year-olds with an irregular breakfast habit after removal of weekend diary days, there were significantly higher intakes of energy (661 (95\% CI 389, 933) kJ (158 (95\% CI 93, 223) $\mathrm{kcal})$ ), folate, Ca and I for days on which breakfast was consumed compared with days on which it was not (Table 5). In contrast to the analysis of all diary days, no significant differences in intakes of any of the macronutrients (protein, fat or carbohydrate) were observed and there was no significant difference in $\mathrm{Na}$ intake.

\section{Discussion}

Our findings suggest that the overall nutritional profile of the children in terms of fibre and micronutrient intake was superior in regular breakfast consumers, for whom higher energyadjusted intakes of fibre, folate, $\mathrm{Ca}, \mathrm{Fe}$ and I were observed compared with breakfast skippers. These findings are supported by our observation that significantly higher proportions of breakfast-consuming children met their RNI of folate, vitamin C, $\mathrm{Ca}, \mathrm{Fe}$ and I compared with breakfast skippers.

In accordance with previous studies ${ }^{(21,23,25)}$, for both the between and within-person analyses and both age groups a lack of breakfast was associated with lower Ca intakes. A recent Mexican study of breakfast dietary patterns among 4-13-yearold children ( $n$ 3760) found that the differences in overall daily nutrient intake profile between breakfast consumers and skippers varied with the type of breakfast consumed, but all breakfast types were associated with a higher daily intake of $\mathrm{Ca}$ than breakfast skipping ${ }^{(22)}$. This is a particularly important

Table 3. Comparison of daily nutrient intakes for children aged 4-18 years with different breakfast habits

(Mean values and standard deviations)

\begin{tabular}{|c|c|c|c|c|c|c|c|c|}
\hline & \multicolumn{2}{|c|}{$\begin{array}{l}\text { Breakfast no diary } \\
\text { days }(n 289)\end{array}$} & \multicolumn{2}{|c|}{$\begin{array}{l}\text { Breakfast at least one but } \\
\text { not all diary days ( } n \text { 879) }\end{array}$} & \multicolumn{2}{|c|}{$\begin{array}{l}\text { Breakfast every } \\
\text { diary day }(n 518)\end{array}$} & \multirow{2}{*}{$\frac{\text { ANOVA }(n \text { 1686) }}{P}$} & \multirow{2}{*}{$\frac{\text { ANCOVA }(n 1416)^{\star}}{P}$} \\
\hline & Mean & SD & Mean & SD & Mean & SD & & \\
\hline Energy (\% EAR) & 71.0 & $22 \cdot 1$ & $82 \cdot 2$ & $22 \cdot 5$ & $92 \cdot 4$ & $21 \cdot 3$ & $<0.001 \dagger$ & $0.009 \dagger$ \\
\hline Protein (\% energy) $\ddagger$ & 14.9 & 3.5 & 14.6 & $2 \cdot 6$ & $14 \cdot 8$ & 2.5 & 0.309 & 0.041 \\
\hline Fat (\% energy) & 34.2 & $5 \cdot 3$ & $33 \cdot 8$ & 4.8 & 33.1 & 4.6 & $0.005 \dagger$ & $0.005 \dagger$ \\
\hline $\mathrm{CHO}$ (\% energy) & 49.7 & $6 \cdot 1$ & $51 \cdot 3$ & $5 \cdot 3$ & $52 \cdot 1$ & 4.8 & $<0.001 \dagger$ & $0.010 \dagger$ \\
\hline NMES (\% energy)‡ & $15 \cdot 5$ & $7 \cdot 1$ & $15 \cdot 3$ & $5 \cdot 8$ & 14.5 & $5 \cdot 4$ & 0.030 & 0.034 \\
\hline Fibre (g/4184 kJ (1000 kcal) energy) & 6.5 & 1.9 & $7 \cdot 0$ & 1.8 & 7.5 & 1.9 & $<0.001 \dagger$ & $<0.001 \dagger$ \\
\hline Folate $(\mu \mathrm{g} / 4184 \mathrm{~kJ}(1000 \mathrm{kcal})$ energy $) \S$ & 114 & 39 & 124 & 39 & 134 & 41 & $<0.001 \dagger$ & $<0.001 \dagger$ \\
\hline Vitamin C (mg/4184 kJ (1000 kcal) energy)§ & 44.6 & 29.4 & 51.5 & $34 \cdot 8$ & $56 \cdot 7$ & $32 \cdot 6$ & $<0.001 \dagger$ & 0.472 \\
\hline $\mathrm{Na}(\mathrm{mg} / 4184 \mathrm{~kJ}(1000 \mathrm{kcal})$ energy) $\ddagger \|$ & 1262 & 314 & 1255 & 284 & 1198 & 220 & 0.027 & 0.127 \\
\hline $\mathrm{Ca}(\mathrm{mg} / 4184 \mathrm{~kJ}(1000 \mathrm{kcal})$ energy)\| & 426 & 132 & 471 & 140 & 532 & 143 & $<0.001 \dagger$ & $<0.001 \dagger$ \\
\hline $\mathrm{Fe}(\mathrm{mg} / 4184 \mathrm{~kJ}$ (1000 kcal) energy) & $5 \cdot 2$ & 1.5 & 5.5 & 1.2 & $5 \cdot 8$ & 1.3 & $<0.001 \dagger$ & $<0.001 \dagger$ \\
\hline I ( $\mu \mathrm{g} / 4184 \mathrm{~kJ}(1000 \mathrm{kcal})$ energy $) \S$ & 68.0 & $30 \cdot 8$ & $77 \cdot 3$ & $37 \cdot 2$ & 89.8 & $35 \cdot 8$ & $<0.001 \dagger$ & $<0.001 \dagger$ \\
\hline
\end{tabular}

EAR, estimated average requirement of energy as set by the Scientific Advisory Committee on Nutrition; CHO, carbohydrate; NMES, non-milk extrinsic sugars.

* ANOVA adjusted for the covariates: age, sex, BMI, ethnicity (white/non-white) and equivalised household income (using McClements equivalence scale); sample size reduced by 270 cases due to missing values for BMI and equivalised income.

$\dagger P 0.01$ is considered significant.

$\ddagger$ Due to inequality of variances for these variables ANOVA and ANCOVA performed after random sample selection to form three equal groups of 245 cases ( $n 735$ ).

$\S$ Natural logarithm transformation applied to calculate significance; means and standard deviations shown for untransformed variables.

II Square root transformation applied to calculate significance; means and standard deviations shown for untransformed variables. 
Table 4(a). Within-person difference in daily nutrient intakes for days on which breakfast consumed compared with days on which breakfast not consumed, 4-18-year-olds ( $n$ 879) (Mean values and standard deviations; mean differences and $95 \%$ confidence intervals)

\begin{tabular}{|c|c|c|c|c|c|c|c|c|c|c|}
\hline & \multicolumn{2}{|c|}{ Non-breakfast days } & \multicolumn{2}{|c|}{ Breakfast days } & \multicolumn{3}{|c|}{$t$ Test paired difference } & \multicolumn{3}{|c|}{ Adjusted paired difference ${ }^{\star}$} \\
\hline & Mean & SD & Mean & SD & Mean difference & $95 \% \mathrm{Cl}$ & $P$ & Mean difference & $95 \% \mathrm{Cl}$ & $P$ \\
\hline Energy (kJ) & 6816 & 2301 & 7201 & 2238 & 385 & 251,519 & $<0.001 \dagger$ & 364 & 218,506 & $<0.001 \dagger$ \\
\hline Energy (kcal) & 1629 & 550 & 1721 & 535 & 92 & 60,124 & $<0.001 \dagger$ & 87 & 52,121 & $<0.001 \dagger$ \\
\hline Protein (\% energy) & $15 \cdot 1$ & 3.8 & 14.5 & 3.2 & -0.57 & $-0.85,-0.30$ & $<0.001 \dagger$ & -0.66 & $-0.96,-0.35$ & $<0.001 \dagger$ \\
\hline Fat (\% energy) & 33.9 & $6 \cdot 6$ & 33.3 & $5 \cdot 8$ & -0.58 & $-1.07,-0.10$ & 0.018 & -0.49 & $-1.02,0.05$ & 0.075 \\
\hline $\mathrm{CHO}$ (\% energy) & $50 \cdot 7$ & 7.6 & $52 \cdot 0$ & $6 \cdot 3$ & 1.29 & $0.76,1.82$ & $<0.001 \dagger$ & 1.28 & $0.71,1.86$ & $<0.001 \dagger$ \\
\hline NMES (\% energy) & $15 \cdot 3$ & $7 \cdot 7$ & $15 \cdot 1$ & $7 \cdot 0$ & -0.26 & $-0.79,0.27$ & 0.339 & -0.21 & $-0.78,0.37$ & 0.483 \\
\hline Fibre (g/4184 kJ (1000 kcal) energy) & $7 \cdot 0$ & $2 \cdot 4$ & $7 \cdot 1$ & $2 \cdot 1$ & 0.11 & $-0.06,0.27$ & 0.215 & 0.10 & $-0.08,0.27$ & 0.272 \\
\hline Folate $(\mu \mathrm{g} / 4184 \mathrm{~kJ}(1000 \mathrm{kcal})$ energy $) \ddagger$ & 123 & 50 & 129 & 50 & 5.9 & $0.03,0.09$ & $<0.001 \dagger$ & $5 \cdot 2$ & $0.03,0.09$ & $<0.001 \dagger$ \\
\hline Vitamin C (mg/4184 kJ (1000 kcal) energy)‡ & $52 \cdot 1$ & 43.2 & 52.7 & 39.5 & 0.6 & $-0.002,0.114$ & 0.057 & 0.3 & $-0.03,0.10$ & 0.257 \\
\hline $\mathrm{Na}(\mathrm{mg} / 4184 \mathrm{~kJ}(1000 \mathrm{kcal})$ energy $) \S$ & 1283 & 371 & 1237 & 348 & -47 & $-1.03,-0.22$ & $0.002 \dagger$ & -55 & $-1 \cdot 19,-0.30$ & $0.001 \dagger$ \\
\hline $\mathrm{Ca}(\mathrm{mg} / 4184 \mathrm{~kJ}(1000 \mathrm{kcal})$ energy $) \S$ & 455 & 173 & 491 & 165 & 36 & $0.64,1.15$ & $<0.001 \dagger$ & 36 & $0.60,1 \cdot 16$ & $<0.001 \dagger$ \\
\hline $\mathrm{Fe}(\mathrm{mg} / 4184 \mathrm{~kJ}$ (1000 kcal) energy) & 5.5 & 1.6 & $5 \cdot 7$ & 1.6 & $0 \cdot 18$ & $0.05,0.30$ & $0.004 \dagger$ & 0.17 & $0.03,0.30$ & 0.016 \\
\hline I ( $\mu \mathrm{g} / 4184 \mathrm{~kJ}(1000 \mathrm{kcal})$ energy) $\ddagger$ & $77 \cdot 2$ & $56 \cdot 3$ & 79.2 & 41.5 & 1.9 & $0.02,0.09$ & $0.001 \dagger$ & 1.3 & $0.01,0.09$ & $0.007 \dagger$ \\
\hline
\end{tabular}

CHO, carbohydrate; NMES, non-milk extrinsic sugars

* Repeated measures ANOVA adjusted for the covariates: age, sex, BMI, ethnicity (white/non-white) and equivalised household income (using McClements equivalence scale). Sample size reduced by 145 cases ( $n 734$ ) due to missing values for BMI and equivalised income.

$\dagger>0.01$ is considered significant.

Pans

\$ Square root transformation applied to calculate significance; means, standard deviations and mean differences shown for untransformed variables.

Table 4(b). Within-person difference in daily nutrient intakes for days on which breakfast consumed compared with days on which breakfast not consumed, 4-10-year-olds ( $n$ 384)

(Mean values and standard deviations; mean differences and $95 \%$ confidence intervals)

\begin{tabular}{|c|c|c|c|c|c|c|c|c|c|c|}
\hline & \multicolumn{2}{|c|}{ Non-breakfast days } & \multicolumn{2}{|c|}{ Breakfast days } & \multicolumn{3}{|c|}{$t$ Test paired difference } & \multicolumn{3}{|c|}{ Adjusted paired difference* } \\
\hline & Mean & SD & Mean & SD & Mean difference & $95 \% \mathrm{Cl}$ & $P$ & Mean difference & $95 \% \mathrm{Cl}$ & $P$ \\
\hline Energy $(\mathrm{kJ})$ & 6188 & 1854 & 6381 & 1485 & 192 & 25,356 & 0.023 & 197 & 17,377 & 0.032 \\
\hline Energy (kcal) & 1479 & 443 & 1525 & 355 & 46 & 6,85 & 0.023 & 47 & 4,90 & 0.032 \\
\hline Protein (\% energy) & 14.8 & 3.4 & 14.6 & $2 \cdot 8$ & -0.26 & $-0.63,0.10$ & 0.159 & -0.36 & $-0.76,0.03$ & 0.073 \\
\hline Fat (\% energy) & 33.9 & 6.5 & 33.1 & $5 \cdot 3$ & -0.86 & $-1.54,-0.18$ & 0.014 & -0.77 & $-1.52,-0.01$ & 0.048 \\
\hline $\mathrm{CHO}$ (\% energy) & $51 \cdot 2$ & $7 \cdot 1$ & $52 \cdot 3$ & $5 \cdot 8$ & $1 \cdot 14$ & $0.39,1.89$ & $0.003 \dagger$ & $1 \cdot 15$ & $0.35,1.94$ & $0.005 \dagger$ \\
\hline NMES (\% energy) & $15 \cdot 1$ & $7 \cdot 3$ & 14.7 & $5 \cdot 7$ & -0.40 & $-1.08,0.29$ & 0.255 & -0.56 & $-1.32,0.19$ & 0.142 \\
\hline Fibre (g/4184 kJ (1000 kcal) energy) & $7 \cdot 0$ & $2 \cdot 3$ & 7.3 & $2 \cdot 0$ & 0.37 & $0.14,0.61$ & $0.002 \dagger$ & 0.42 & $0.17,0.67$ & $0.001 \dagger$ \\
\hline Folate ( $\mu \mathrm{g} / 4184 \mathrm{~kJ}(1000 \mathrm{kcal})$ energy) $\ddagger$ & 125 & 46 & 133 & 45 & 8.5 & $0.04,0.12$ & $<0.001 \dagger$ & 8.4 & $0.04,0.12$ & $<0.001 \dagger$ \\
\hline Vitamin C (mg/4184 kJ (1000 kcal) energy)‡ & $56 \cdot 0$ & 43.5 & 59.4 & 37.6 & 3.4 & $0.54,0.21$ & $0.001 \dagger$ & 3.5 & $0.05,0.23$ & $0.002 \dagger$ \\
\hline $\mathrm{Na}(\mathrm{mg} / 4184 \mathrm{~kJ}(1000 \mathrm{kcal})$ energy $) \S$ & 1259 & 374 & 1213 & 299 & -46 & $-1.09,0.04$ & 0.069 & -46 & $-1.15,0.08$ & 0.085 \\
\hline $\mathrm{Ca}(\mathrm{mg} / 4184 \mathrm{~kJ}(1000 \mathrm{kcal})$ energy $) \S$ & 494 & 190 & 524 & 176 & 29 & $0.34,1 \cdot 12$ & $<0.001 \dagger$ & 33 & $0.38,1.24$ & $<0.001 \dagger$ \\
\hline $\mathrm{Fe}(\mathrm{mg} / 4184 \mathrm{~kJ}(1000 \mathrm{kcal})$ energy) & 5.5 & 1.6 & 5.7 & 1.5 & 0.26 & $0.08,0.44$ & $0.005 \dagger$ & 0.22 & $0.03,0.42$ & 0.027 \\
\hline I $(\mu \mathrm{g} / 4184 \mathrm{~kJ}(1000 \mathrm{kcal})$ energy $) \ddagger$ & 85.8 & $50 \cdot 1$ & 90.2 & $47 \cdot 2$ & 4.4 & $0.02,0.13$ & $0.005 \dagger$ & $5 \cdot 1$ & $0.03,0.14$ & $0.005+$ \\
\hline
\end{tabular}

CHO, carbohydrate; NMES, non-milk extrinsic sugars.

Repeated measures ANOVA adjusted for the covariates: age, sex, BMI, ethnicity (white/non-white) and equivalised household income (using McClements equivalence scale). Sample size reduced by sixty-two cases ( $n$ 322) due to missing values for BMI and equivalised income.

$\dagger \leq 0.01$ is considered significant.

F Natural logarithm transformation applied to calculate significance; means, standard deviations and mean differences shown for untransformed variables.

$\S$ Square root transformation applied to calculate significance; means, standard deviations and mean differences shown for untransformed variables. 
Table 4(c). Within-person difference in daily nutrient intakes for days on which breakfast consumed compared with days on which breakfast not consumed, 11-18-year-olds ( $n$ 495) (Mean values and standard deviations; mean differences and $95 \%$ confidence intervals)

\begin{tabular}{|c|c|c|c|c|c|c|c|c|c|c|}
\hline & \multicolumn{2}{|c|}{ Non-breakfast days } & \multicolumn{2}{|c|}{ Breakfast days } & \multicolumn{3}{|c|}{$t$ Test paired difference } & \multicolumn{3}{|c|}{ Adjusted paired difference ${ }^{*}$} \\
\hline & Mean & SD & Mean & SD & Mean difference & $95 \% \mathrm{Cl}$ & $P$ & Mean difference & $95 \% \mathrm{Cl}$ & $P$ \\
\hline Energy (kJ) & 7305 & 2489 & 7841 & 2502 & 536 & 335,732 & $<0.001 \dagger$ & 494 & 276,707 & $<0.001 \dagger$ \\
\hline Energy (kcal) & 1746 & 595 & 1874 & 598 & 128 & 80,175 & $<0.001 \dagger$ & 118 & 66,169 & $<0.001 \dagger$ \\
\hline Protein (\% energy) & $15 \cdot 3$ & 4.1 & 14.5 & 3.4 & -0.82 & $-1.22,-0.42$ & $<0.001 \dagger$ & -0.88 & $-1.33,-0.44$ & $<0.001 \dagger$ \\
\hline Fat (\% energy) & 33.8 & 6.7 & 33.4 & $6 \cdot 1$ & -0.37 & $-1.04,0.30$ & 0.281 & -0.27 & $-1.00,0.47$ & 0.478 \\
\hline $\mathrm{CHO}$ (\% energy) & $50 \cdot 3$ & 7.9 & 51.7 & 6.6 & 1.41 & $0 \cdot 67,2 \cdot 15$ & $<0.001 \dagger$ & 1.39 & $0.58,2.20$ & $0.001 \dagger$ \\
\hline NMES (\% energy) & $15 \cdot 5$ & 8.0 & $15 \cdot 4$ & $7 \cdot 8$ & -0.15 & $-0.93,0.63$ & 0.704 & 0.08 & $-0.76,0.91$ & 0.859 \\
\hline Fibre (g/4184 kJ (1000 kcal) energy) & 7.0 & 2.5 & 6.9 & $2 \cdot 2$ & $-0 \cdot 10$ & $-0.33,0.13$ & 0.383 & $-0 \cdot 16$ & $-0.40,0.09$ & 0.214 \\
\hline Folate $(\mu \mathrm{g} / 4184 \mathrm{~kJ}(1000 \mathrm{kcal})$ energy $) \ddagger$ & 122 & 52 & 126 & 54 & 4.0 & $0.01,0.09$ & 0.023 & $2 \cdot 7$ & $-0.002,0.085$ & 0.062 \\
\hline Vitamin C (mg/4184 kJ (1000 kcal) energy)‡ & 49.1 & $42 \cdot 7$ & $47 \cdot 4$ & $40 \cdot 1$ & $-1 \cdot 7$ & $-0.09,0.08$ & 0.917 & $-2 \cdot 1$ & $-0.13,0.04$ & 0.289 \\
\hline $\mathrm{Na}$ (mg/4184 kJ (1000 kcal) energy)§ & 1302 & 368 & 1255 & 380 & -47 & $-1 \cdot 28,-0.14$ & 0.015 & -61 & $-1.53,-0.28$ & $0.005 \dagger$ \\
\hline $\mathrm{Ca}(\mathrm{mg} / 4184 \mathrm{~kJ}(1000 \mathrm{kcal})$ energy $) \S$ & 424 & 152 & 466 & 152 & 42 & $0.68,1.36$ & $<0.001 \dagger$ & 38 & $0.57,1.31$ & $<0.001 \dagger$ \\
\hline Fe (mg/4184 kJ (1000 kcal) energy) & $5 \cdot 5$ & 1.6 & $5 \cdot 6$ & 1.6 & $0 \cdot 11$ & $-0.05,0.28$ & 0.178 & $0 \cdot 12$ & $-0.07,0.30$ & 0.204 \\
\hline I $(\mu \mathrm{g} / 4184 \mathrm{~kJ}(1000 \mathrm{kcal})$ energy $) \ddagger$ & $70 \cdot 6$ & 59.9 & $70 \cdot 5$ & $34 \cdot 1$ & 0.0 & $-0.003,0.092$ & 0.063 & $-1 \cdot 8$ & $-0.02,0.08$ & 0.258 \\
\hline
\end{tabular}

$\mathrm{CHO}$, carbohydrate; NMES, non-milk extrinsic sugars.

* Repeated measures ANOVA adjusted for the covariates: age, sex, BMI, ethnicity (white/non-white) and equivalised household income (using McClements equivalence scale). Sample size reduced by eighty-three cases ( $n$ 412) due to missing values for BMI and equivalised income.

$\dagger P \leq 0.01$ is considered significant.

Natural logarithm transformation applied to calculate significance; means, standard deviations and mean differences shown for untransformed variables.

$\S$ Square root transformation applied to calculate significance; means, standard deviations and mean differences shown for untransformed variables.

Table 5. Within-person difference in daily nutrient intakes for days on which breakfast consumed compared with days on which breakfast not consumed, no Saturdays or Sundays, 4-18-year-olds ( $n$ 365) (Mean values and standard deviations; mean differences and $95 \%$ confidence intervals)

\begin{tabular}{|c|c|c|c|c|c|c|c|c|c|c|}
\hline & \multicolumn{2}{|c|}{ Non-breakfast days } & \multicolumn{2}{|c|}{ Breakfast days } & \multicolumn{3}{|c|}{$t$ Test paired difference } & \multicolumn{3}{|c|}{ Adjusted paired difference ${ }^{*}$} \\
\hline & Mean & SD & Mean & SD & Mean difference & $95 \% \mathrm{Cl}$ & $P$ & Mean difference & $95 \% \mathrm{Cl}$ & $P$ \\
\hline Energy (kJ) & 6443 & 2590 & 7063 & 2389 & 619 & 377,866 & $<0.001 \dagger$ & 661 & 389,933 & $<0.001 \dagger$ \\
\hline Energy (kcal) & 1540 & 619 & 1688 & 571 & 148 & 90,207 & $<0.001 \dagger$ & 158 & 93,223 & $<0.001 \dagger$ \\
\hline Protein (\% energy) & $15 \cdot 2$ & 4.4 & 14.6 & 4.0 & -0.52 & $-1.06,0.02$ & 0.061 & -0.61 & $-1.22,0.01$ & 0.052 \\
\hline Fat (\% energy) & 33.4 & 7.8 & 33.5 & $7 \cdot 1$ & 0.11 & $-0.77,0.99$ & 0.807 & 0.13 & $-0.88,1 \cdot 13$ & 0.802 \\
\hline $\mathrm{CHO}$ (\% energy) & 51.1 & 8.2 & $51 \cdot 7$ & 7.7 & 0.56 & $-0.38,1.49$ & 0.240 & 0.65 & $-0.40,1.71$ & 0.225 \\
\hline NMES (\% energy) & $15 \cdot 2$ & 8.6 & $15 \cdot 3$ & 8.0 & 0.13 & $-0.82,1.09$ & 0.782 & 0.38 & $-0.69,1.46$ & 0.484 \\
\hline Fibre (g/4184 kJ (1000 kcal) energy) & $7 \cdot 2$ & $2 \cdot 8$ & $7 \cdot 0$ & 2.5 & -0.21 & $-0.53,0.10$ & 0.186 & -0.29 & $-0.62,0.04$ & 0.080 \\
\hline Folate $(\mu \mathrm{g} / 4184 \mathrm{~kJ}(1000 \mathrm{kcal})$ energy $) \ddagger$ & 120 & 53 & 127 & 52 & 7.7 & $0.03,0.13$ & $0.003+$ & 9.0 & $0.03,0.14$ & $0.004 \dagger$ \\
\hline Vitamin C (mg/4184 kJ (1000 kcal) energy)§ & 51.3 & 48.4 & 53.7 & $45 \cdot 2$ & $2 \cdot 4$ & $-0.05,0.58$ & 0.100 & 1.4 & $-0.19,0.52$ & 0.369 \\
\hline $\mathrm{Na}(\mathrm{mg} / 4184 \mathrm{~kJ}(1000 \mathrm{kcal})$ energy $) \S$ & 1270 & 412 & 1236 & 411 & -35 & $-1 \cdot 21,0.26$ & 0.206 & -41 & $-1.39,0.24$ & 0.165 \\
\hline $\mathrm{Ca}(\mathrm{mg} / 4184 \mathrm{~kJ}(1000 \mathrm{kcal})$ energy $) \S$ & 434 & 181 & 475 & 172 & 41 & $0.59,1.52$ & $<0.001 \dagger$ & 43 & $0.60,1.64$ & $<0.001 \dagger$ \\
\hline $\mathrm{Fe}(\mathrm{mg} / 4184 \mathrm{~kJ}(1000 \mathrm{kcal})$ energy) & 5.4 & 1.9 & $5 \cdot 6$ & 1.7 & 0.16 & $-0.06,0.37$ & 0.149 & 0.15 & $-0.08,0.38$ & 0.208 \\
\hline I $(\mu \mathrm{g} / 4184 \mathrm{~kJ}$ (1000 kcal) energy) $\ddagger$ & 70.6 & $44 \cdot 3$ & $75 \cdot 1$ & 44.4 & 4.5 & $0.02,0.15$ & $0.007 \dagger$ & 5.5 & $0.03,0.17$ & $0.008 \dagger$ \\
\hline
\end{tabular}

$\mathrm{CHO}$, carbohydrate; NMES, non-milk extrinsic sugars.

* Repeated measures ANOVA adjusted for the covariates: age, sex, BMI, ethnicity (white/non-white) and equivalised household income (using McClements equivalence scale). Sample size reduced by sixty-seven cases ( $n$ 298) due to missing values for BMl and equivalised income.

$\dagger P \leq 0.01$ is considered significant.

\# Natural logarithm transformation applied to calculate significance for untransformed variables.

$\S$ Square root transformation applied to calculate significance for untransformed variables. 
finding given that $\mathrm{Ca}$ is a vital nutrient for bone growth and needs in childhood are high due to rapid growth and bone mass accretion $^{(52)}$. In the within-person analysis, higher intakes of fibre, folate, vitamin $\mathrm{C}$ and I were observed on the days that the 4-10-year-olds ate breakfast, but no significant difference in intakes of these micronutrients was noted for the 11-18-yearolds. This suggests that more foods rich in these micronutrients (e.g. fortified cereals, milk and fruit juice) are consumed for breakfast in the younger compared with the older age group, possibly due to greater parental supervision of the younger children's meals. A Spanish study of 8-17-year-old children ( $n$ 4332) evaluating the utility of a breakfast quality index, in which points were awarded for the consumption of cereals, fruits, vegetables and dairy products at breakfast, found that the score decreased with age $(P=0.001)^{(53)}$. For the within-person analyses including all diary days, intakes of $\mathrm{Na}$ are significantly higher on no breakfast days for 4-18-year-olds and 11-18-yearolds, but not 4-10-year-olds, suggesting that the older age group may compensate for the lack of breakfast by the consumption of salty snacks later in the day (protein intakes are also higher on non-breakfast days for the older but not the younger group). However this association was no longer significant when weekend diary days were removed from the within-person analysis (and is not present in the between-person analysis), so may simply be a reflection of a different dietary pattern at weekends (e.g. late or no breakfast with greater daily amounts of protein rich and salty foods) in the older age group.

We did not find any evidence to support the oft-quoted hypothesis that breakfast skipping leads to increased overall daily energy intake due to compensatory overeating later in the day $^{(9,54)}$. On the contrary, in our analyses we observed that breakfast skipping was associated with either no difference or a significantly lower daily energy intake. These results are in accordance with those of most (but not all) recent observational studies of children ${ }^{(9,18,20-22)}$. Similarly, small cross-over trials in children have reported no significant differences in overall daily energy intakes on breakfast and non-breakfast days ${ }^{(55,56)}$. The findings on energy intake in this and other studies might suggest caution when recommending breakfast consumption as a weight management tool in children, despite the large body of epidemiological evidence linking breakfast skipping and excess weight in children. Also, they undermine the argument for a causal link between breakfast skipping and overweight and obesity based on excess energy intake. Interestingly, a large, longitudinal US study of breakfast habits and weight gain in 9-14-year-olds found that, although breakfast skipping was associated with higher BMI overall, overweight breakfast skippers tended to lose weight over the study period compared with overweight breakfast eaters, whereas the reverse was true for normal weight breakfast skippers compared with normal weight breakfast eaters ${ }^{(57)}$. Alternative theories for the link observed between adiposity and breakfast skipping include the presence of confounding factors such as sleep duration and circadian rhythms ${ }^{(12)}$, and lower physical activity levels in breakfast skippers $(4,58,59)$.

The results of previous studies of children investigating the effect on overall macronutrient profile of breakfast habit vary $^{(23)}$. In this study small but statistically significant variations in macronutrient profile were noted, with the proportion of carbohydrate consumed generally higher for breakfast consumers (for the between-person analysis) and on breakfast days (for the within-person analysis), at the expense of either protein or fat intake. However, no significant variations in macronutrient profile when comparing intakes on breakfast days with those on non-breakfast days were found for the within-person analysis after weekend diary days had been removed from the analysis. This may be due to a different dietary pattern for the children at the weekend. In studies that have analysed breakfast habit by type of breakfast consumed, different overall daily nutrient intake profiles have been associated with different breakfast types ${ }^{(20,22)}$. For example, in a large US cross-sectional study of breakfast consumption in 9-18-year-olds ( $n$ 9659), consumers of ready-to-eat cereals had higher intakes of carbohydrate and lower intakes of fat than breakfast skippers, but for consumers of other types of breakfast there was no significant difference in intakes of these macronutrients compared with breakfast skippers ${ }^{(18)}$.

No link was observed between overall NMES intake (as a percentage of energy) and breakfast consumption. In the withinperson analysis we observed no significant difference in the proportion of fat or NMES consumed between breakfast and nonbreakfast days, suggesting that intermittent breakfast skipping did not lead to an increase in consumption of poor quality, high sugar and high fat foods and beverages on non-breakfast days in this study population, as has been postulated elsewhere ${ }^{(54)}$.

In our analysis of the characteristics of the children in the sample we found no significant differences in the proportion of normal weight, overweight and obese children in each breakfast habit category, which is at odds with the findings of some but not all cross-sectional studies ${ }^{(4-7)}$ in children. In line with other studies in children $^{(9,23,60,61)}$, we observed higher levels of breakfast skipping in girls and older children and lower mean household incomes for breakfast skippers. There is evidence that frequency of breakfast skipping in teenagers is related to dieting and other weight-control behaviours ${ }^{(9)}$, which may explain its greater incidence in girls ${ }^{(62)}$. A cross-sectional study of UK 11-16-year-olds ( $n$ 1019) found that almost twice as many girls reported dieting and those girls that were dieting were three times more likely to skip breakfast than nondieters ${ }^{(63)}$. In our study a significantly higher proportion of girls in the 11-18-year-old age group stated that they were currently dieting than boys. However, reported dieting behaviour did not vary significantly with breakfast habit for the girls in our sample, but this could be due to the smaller sample size ( $n$ 224) resulting in lower statistical power (dieting data were only available for the last 2 years of the NDNS RP 2008-2012).

The greater level of breakfast skipping among older children may be influenced by a reduction in parental control enforcing a 'healthy' breakfast habit. It may also reflect the shift in circadian rhythms in adolescence to a later wake/sleep cycle ${ }^{(64)}$. During puberty an individual's chronotype, that is their preference for an early or late wake/sleep cycle, shifts from early to late, with sleep schedules moving progressively later between the ages of 10 and 20 years ${ }^{(65)}$. During the school week children's wake/sleep cycle is dictated by the school routine but at the weekend the wake/sleep cycle is generally less restricted. 
A study of food logs of German adolescents ( $n$ 152, mean age 13.23 years) found that wake times at the weekend were on average $2 \mathrm{~h} 40 \mathrm{~min}$ later, which translated to later breakfast times: the average breakfast time on weekdays was 06.36 hours, compared with 09.15 hours at weekends ${ }^{(66)}$. Wake time data were not available for the study sample, so in our analysis we have defined breakfast in relation to a specific, fixed time period, namely 06.00-08.59 hours, rather than relate it to intake within a certain time of waking. However, because of this weekend shift in breakfast times a meal eaten shortly after waking may not fall within this fixed time period. To address this issue, a separate within-person analysis was carried out after removing weekend diary days.

Chronotype not only varies with age but it also depends on genetic and environmental factors ${ }^{(65,67)}$. Chronotype may be an important confounding factor in the between-person analysis in this and other studies. There is evidence that not only are adolescents with later chronotypes more likely to skip breakfast, they are also more likely to have poorer overall diets ${ }^{(66)}$ and lower levels of physical activity ${ }^{(68)}$. The impact of chronotype and other possible residual confounding factors, which are always an issue in cross-sectional studies, should be less of a factor in the within- compared with the between-person analysis. Adjustments have been made in the ANOVA for age, sex, BMI, ethnicity and equivalised household income, however we were not able to adjust for physical activity level due to lack of complete and consistent data across all ages ${ }^{(35)}$.

We relied on data from 4-d estimated food diaries and an objective definition of breakfast to categorise children by their breakfast habit, rather than on responses to an eating habits questionnaire. This avoids issues resulting from inconsistent personal definitions of breakfast. Nevertheless, it is recognised that the $418 \mathrm{~kJ}$ ( $100 \mathrm{kcal})$ threshold chosen for our definition of breakfast is, to some extent, arbitrary. Also, the fixed time frame we used to define breakfast may result in a late weekend breakfast not being captured by the definition, however this was allowed for in the within-person analysis by removing weekend diary days.

In common with other dietary surveys, there is a possibility of mis-reporting of dietary intakes. Doubly labelled water techniques used in the NDNS RP to validate energy intakes for a sample of survey participants suggest that under-reporting may have been more prevalent for the children in the 11-18 years age group, who completed their own food diaries, in contrast to children in the younger age group, whose diaries were completed by their parents ${ }^{(69)}$. The results of our sensitivity analysis suggest that there were higher levels of mis-reporting in the older age group. Where appropriate, to assess the impact of mis-reporting we reran analyses omitting implausible reporters.

Many different methods of dietary data collection have been used in previous studies of breakfast habits in children ${ }^{(23)}$, with varying degree of reliability. Strengths of our study include the large sample size and the method of dietary assessment used, namely a 4-d estimated food diary. In other recent crosssectional surveys of children's breakfast habits and nutrient intakes $^{(18-22)}$, the $24-\mathrm{h}$ recall method was used, which relies heavily on the accuracy of the child's or their parent's memory. We are aware of two small cross-over studies involving US children which report on the impact of breakfast skipping on overall daily energy intake ${ }^{(55,56)}$ but, to our knowledge, there has not yet been a randomised, controlled trial assessing the impact of breakfast consumption in children on intakes of individual macro- and micronutrients. The approach we adopted of approximating a cross-over study design (thereby reducing residual confounding) in free living individuals by conducting a within-person analysis of subjects with an irregular breakfast habit has been carried out previously in adults $^{(70)}$, but not children.

In our study we examined how macro- and micronutrient intakes, plus energy intake, varied with children's breakfast habit. A possible topic for future research would be to look at associations in UK children between breakfast habit and daily intakes of specific foods, incorporating a diet quality index ${ }^{(71)}$ to further investigate associations between breakfast habit and overall diet quality. It would also be interesting to investigate how the quality of the breakfast foods consumed by UK children varies with age, to ascertain if the differences we noted between the two age groups in our within-person analysis might be attributed to lower quality breakfasts in the older age group. Work has already been carried out on developing breakfast quality indices for use in relation to children and adolescents in a Mediterranean setting ${ }^{(16,53,71)}$; further work is required to adapt these for use in a UK population.

In conclusion, the connection between the consumption of breakfast and good health appears to involve many different factors, and is still some way from being fully elucidated. A causal link with obesity is, as yet, unsupported by the available evidence ${ }^{(72)}$. However, this study adds to the existing body of data linking breakfast consumption with higher quality dietary intake in school-age children, particularly the 4-10 years age group, supporting the promotion of breakfast as an important element of a healthy dietary pattern in children.

\section{Acknowledgements}

The authors would like to thank everyone involved in the National Diet and Nutrition Survey Rolling Programme (20082012), the data from which formed the basis of this study.

This research received no specific grant from any funding agency, commercial or not-for-profit sectors.

J. D. C. formulated the research question, prepared the data for analysis, analysed and interpreted the data and wrote the manuscript, all under the supervision of G. K. P. and L. P. All authors approved the final draft before publication.

None of the authors has any conflicts of interest to declare.

\section{References}

1. Public Health England (2013) Get off to a great start with a healthy breakfast! www.nhs.uk/Change4Life/Breakfast-forlife.aspx (accessed November 2016).

2. Rampersaud GC (2009) Benefits of breakfast for children and adolescents: update and recommendations for practitioners. Am J Lifestyle Med 3, 86-103.

3. Moreno LA, Rodriguez G, Fleta J, et al. (2010) Trends of dietary habits in adolescents. Crit Rev Food Sci Nutr 50, 106-112. 
4. Szajewska H \& Ruszczynski M (2010) Systematic review demonstrating that breakfast consumption influences body weight outcomes in children and adolescents in Europe. Crit Rev Food Sci Nutr 50, 113-119.

5. De La Hunty A, Gibson S \& Ashwell M (2013) Does regular breakfast cereal consumption help children and adolescents stay slimmer? A systematic review and meta-analysis. Obes Facts 6, 70-85.

6. Zakrzewski JK, Gillison FB, Cumming S, et al. (2015) Associations between breakfast frequency and adiposity indicators in children from 12 countries. Int J Obes Suppl 5, S80-S88.

7. Kelly Y, Patalay P, Montgomery S, et al. (2016) BMI development and early adolescent psychosocial well-being: UK Millennium Cohort Study. Pediatrics 138, e20160967.

8. Haug E, Rasmussen M, Samdal O, et al. (2010) Overweight in school-aged children and its relationship with demographic and lifestyle factors: results from the WHO-collaborative Health Behaviour in School-aged Children (HBSC) Study. Int J Public Health 54, 167-179.

9. Timlin MT, Pereira MA, Story M, et al. (2008) Breakfast eating and weight change in a 5-year prospective analysis of breakfast eating and weight change in a 5-year prospective analysis of adolescents: Project EAT (Eating Among Teens). Pediatrics 121, 638-645.

10. Dhurandhar EJ, Dawson J, Alcorn A, et al. (2014) The effectiveness of breakfast recommendations on weight loss: a randomized controlled trial. Am J Clin Nutr 100, 507-513.

11. Casazza K, Brown A, Astrup A, et al. (2015) Weighing the evidence of common beliefs in obesity research. Crit Rev Food Sci Nutr 55, 2014-2053.

12. Dhurandhar EJ (2016) True, true, unrelated? A review of recent evidence for a causal influence of breakfast on obesity. Curr Opin Endocrinol Diabetes Obes 23, 384-388.

13. van Nassau F, Singh AS, Cerin E, et al. (2014) The Dutch Obesity Intervention in Teenagers (DOiT) cluster controlled implementation trial: intervention effects and mediators and moderators of adiposity and energy balance-related behaviours. Int J Behav Nutr Phys Act 11, 158-168.

14. Albertson AM, Anderson GH, Crockett SJ, et al. (2003) Readyto-eat cereal consumption: its relationship with BMI and nutrient intake of children aged 4 to 12 years. J Am Diet Assoc 103, 1613-1619.

15. Albertson AM, Affenito SG, Bauserman R, et al. (2009) The relationship of ready-to-eat cereal consumption to nutrient intake, blood lipids, and body mass index of children as they age through adolescence. I Am Diet Assoc 109, 1557-1565.

16. van den Boom A, Serra-Majem L, Ribas L, et al. (2006) The contribution of ready-to-eat cereals to daily nutrient intake and breakfast quality in a Mediterranean setting. $J$ Am Coll Nutr 25, 135-143.

17. Matthys C, De Henauw S, Bellemans M, et al. (2007) Breakfast habits affect overall nutrient profiles in adolescents. Public Health Nutr 10, 413-421.

18. Deshmukh-Taskar PR, Nicklas TA, O'Neil CE, et al. (2010) The relationship of breakfast skipping and type of breakfast consumption with nutrient intake and weight status in children and adolescents: The National Health and Nutrition Examination Survey 1999-2006. J Am Diet Assoc 110, 869-878.

19. Grieger JA \& Cobiac L (2012) Comparison of dietary intakes according to breakfast choice in Australian boys. Eur J Clin Nutr 66, 667-672.

20. Barr SI, DiFrancesco L \& Fulgoni VL (2014) Breakfast consumption is positively associated with nutrient adequacy in Canadian children and adolescents. Br J Nutr 112, 1373-1383.

21. Fayet-Moore F, Kim J, Sritharan N, et al. (2016) Impact of breakfast skipping and breakfast choice on the nutrient intake and body mass index of Australian children. Nutrients 8, 487-498.

22. Afeiche MC, Taillie LS, Hopkins S, et al. (2017) Breakfast dietary patterns among Mexican children are related to totalday diet quality. J Nutr 147, 404-412.

23. Rampersaud GC, Pereira MA, Girard BL, et al. (2005) Breakfast habits, nutritional status, body weight, and academic performance in children and adolescents. J Am Diet Assoc 105, 743-760.

24. Barton BA, Eldridge AL, Thompson D, et al. (2005) The relationship of breakfast and cereal consumption to nutrient intake and body mass index: The National Heart, Lung, and Blood Institute Growth and Health Study. J Am Diet Assoc 105, 1383-1389.

25. Affenito SG, Thompson DR, Barton BA, et al. (2005) Breakfast consumption by African-American and white adolescent girls correlates positively with calcium and fiber intake and negatively with body mass index. J Am Diet Assoc 105 , 938-945.

26. Sjöberg A, Hallberg L, Höglund D, et al. (2003) Meal pattern, food choice, nutrient intake and lifestyle factors in The Göteborg Adolescence Study. Eur J Clin Nutr 57, 1569-1578.

27. Williams P (2007) Breakfast and the diets of Australian children and adolescents: an analysis of data from the 1995 National Nutrition Survey. Int J Food Sci Nutr 58, 201-216.

28. Nicklas TA, Reger C, Myers L, et al. (2000) Breakfast consumption with and without vitamin-mineral supplement use favorably impacts daily nutrient intake of ninth-grade students. J Adolesc Health 27, 314-321.

29. Nicklas TA, O'Neil C \& Myers L (2004) The importance of breakfast consumption to nutrition of children, adolescents, and young adults. Nutr Today 39, 30-39.

30. Sampson A, Dixit S, Meyers A, et al. (1995) The nutritional impact of breakfast consumption on the diets of inner-city African-American elementary school children. I Natl Med Assoc 87, 195-202.

31. Antonogeorgos G, Panagiotakos DB, Papadimitriou A, et al. (2012) Breakfast consumption and meal frequency interaction with childhood obesity. Pediatr Obes 7, 65-72.

32. Berkey C, Rockett H, Gillman M, et al. (2003) Longitudinal study of skipping breakfast and weight change in adolescents. Int J Obes 27, 1258-1266.

33. O'Neil CE, Byrd-Bredbenner C, Hayes D, et al. (2014) The role of breakfast in health: definition and criteria for a quality breakfast. $J$ Acad Nutr Diet 114, S8-S26.

34. Betts JA, Chowdhury EA, Gonzalez JT, et al. (2016) Is breakfast the most important meal of the day? Proc Nutr Soc $\mathbf{7 5}$, 464-474.

35. Public Health England (2014) National Diet and Nutrition Survey Results from Years 1, 2, 3 and 4 (combined) of the Rolling Programme (2008/2009-2011/2012). London: Public Health England. https://www.gov.uk/government/uploads/ system/uploads/attachment_data/file/594361/NDNS_Y1_to_ 4_UK_report_full_text_revised_February_2017.pdf (accessed May 2017).

36. NatCen Social Research, MRC Human Nutrition Research \& University College London (2015) National Diet and Nutrition Survey Years 1-4, 2008/09-2011/12 [computer file], 7th ed. Colchester, Essex: UK Data Archive. http://dx.doi.org/ 10.5255/UKDA-SN-6533-5

37. Lennox A, Fitt E, Whitton C, et al. (2014) Appendix A to National Diet and Nutrition Survey. Results from Years 1-4 (combined) of the Rolling Programme (2008/2009-2011/12). Dietary data collection and editing. London: Public Health England.

38. Bates B, Lennox A, Prentice A, et al. (2014) P2753 National Diet and Nutrition Survey (NDNS) Year 4 Interviewer Project 
Instructions. Colchester, Essex: UK Data Archive. http://dx. doi.org/10.5255/UKDA-SN-6533-5

39. Public Health England (2014) National Diet and Nutrition Survey Rolling Programme Years 1-4 2008/09-2011/12 User Guide for UK Core Sample Data. Colchester, Essex: UK Data Archive. http://dx.doi.org/10.5255/UKDA-SN-6533-5

40. Food Standards Agency (2002) McCance and Widdowson's The Composition of Foods, 6th ed. Cambridge: Royal Society of Chemistry.

41. Scientific Advisory Committee on Nutrition (2015) Carbohydrates and health. https://www.gov.uk/government/publications/sacncarbohydrates-and-health-report (accessed May 2017)

42. Englyst HN, Quigley ME \& Hudson GJ (1994) Determination of dietary fibre as non-starch polysaccharides with gas-liquid chromatographic, high-performance liquid chromatographic or spectrophotometric measurement of constituent sugars. Analyst 119, 1497-1509.

43. Scientific Advisory Committee on Nutrition (2011) Dietary reference values for energy. https://www.gov.uk/government/ uploads/system/uploads/attachment_data/file/339317/SACN Dietary_Reference_Values_for_Energy.pdf (accessed May 2017).

44. Committee on Medical Aspects of Food Policy (1991) Dietary Reference Values for Food Energy and Nutrients for the United Kingdom. London: The Stationery Office.

45. Pot GK, Richards M, Prynne CJ, et al. (2014) Development of the Eating Choices Index (ECI): a four-item index to measure healthiness of diet. Public Health Nutr 17, 1-7.

46. Vanderpump MPJ, Lazarus JH, Smyth PP, et al. (2011) Iodine status of UK schoolgirls: a cross-sectional survey. Lancet $\mathbf{3 7 7}$, 2007-2012.

47. Cole T, Freeman J \& Preece M (1995) Body mass index reference curves for the UK, 1990. Arch. Dis. Child 73, 25-29.

48. Public Health England (2014) P2752 National Diet and Nutrition Survey Year 4 CAPI Interviewer Schedule. Colchester, Essex: UK Data Archive. http://dx.doi.org/10.5255/ UKDA-SN-6533-5

49. McCrory MA, Hajduk CL \& Roberts SB (2002) Procedures for screening out inaccurate reports of dietary energy intake. Public Health Nutr 5, 873-882.

50. Rogan JC \& Keselman HJ (1977) Is the ANOVA F-test robust to variance heterogeneity when sample sizes are equal?: An investigation via a coefficient of variation. Am Educ Res J 14, 493-498.

51. Feise RJ (2002) Do multiple outcome measures require p-value adjustment? BMC Med Res Methodol 2, 8-11.

52. Cashman KD (2002) Calcium intake, calcium bioavailability and bone health. Br J Nutr 87, Suppl. 2, S169-S177.

53. Monteagudo C, Palacin-Arce A, del Mar Bibiloni $\mathrm{M}$, et al. (2013) Proposal for a Breakfast Quality Index (BQI) for children and adolescents. Public Health Nutr 16, 639-644.

54. Miech RA, Kumanyika SK, Stettler N, et al. (2006) Trends in the association of poverty with overweight among US adolescents, 1971-2004. J Am Med Assoc 295, 2385-2393.

55. Leidy HJ \& Racki EM (2010) The addition of a protein-rich breakfast and its effects on acute appetite control and food intake in 'breakfast-skipping' adolescents. Int J Obes $\mathbf{3 4}$, $1125-1133$.
56. Kral TVE, Whiteford LM, Heo M, et al. (2011) Effects of eating breakfast compared with skipping breakfast on ratings of appetite and intake at subsequent meals in 8- to 10 -y-old children. Am J Clin Nutr 93, 284-291.

57. Berkey CS, Rockett HRH, Gillman MW, et al. (2003) Longitudinal study of skipping breakfast and weight change in adolescents. Int J Obes 27, 1258-1266.

58. Schembre SM, Wen CK, Davis JN, et al. (2013) Eating breakfast more frequently is cross-sectionally associated with greater physical activity and lower levels of adiposity in overweight Latina and African American girls. Am J Clin Nutr 98, 275-281.

59. Betts JA, Richardson JD, Chowdhury EA, et al. (2014) The causal role of breakfast in energy balance and health: a randomized controlled trial in lean adults. Am JClin Nutr 100, 539-547.

60. Hoyland A, McWilliams K, Duff R, et al. (2012) Breakfast consumption in UK schoolchildren and provision of school breakfast clubs. Nutr Bull 37, 232-240.

61. Adolphus K, Lawton CL \& Dye L (2013) The effects of breakfast on behavior and academic performance in children and adolescents. Front Hum Neurosci 7, 425.

62. Cohen B, Evers S, Manske S, et al. (2003) Smoking, physical activity and breakfast consumption among secondary school students in a southwestern Ontario community. Can J Public Health 94, 41-44.

63. Lattimore PJ \& Halford JCG (2003) Adolescence and the dietdieting disparity: healthy food choice or risky health behaviour? Br J Health Psychol 8, 451-463.

64. Crowley SJ, Acebo C \& Carskadon MA (2007) Sleep, circadian rhythms, and delayed phase in adolescence. Sleep Med $\mathbf{8}$, 602-612.

65. Roenneberg T, Kuehnle T, Pramstaller PP, et al. (2004) A marker for the end of adolescence. Curr Biol 14, R1038-R1039.

66. Fleig D \& Randler C (2009) Association between chronotype and diet in adolescents based on food logs. Eat Behav 10, $115-118$.

67. Roenneberg T, Kuehnle T, Juda M, et al. (2007) Epidemiology of the human circadian clock. Sleep Med Rev 11, 429-438.

68. Schaal S, Peter M \& Randler C (2010) Morningnesseveningness and physical activity in adolescents. Int J Sport Exerc Psychol 8, 147-159.

69. Coulthard JD \& Pot GK (2016) The timing of the evening meal: how is this associated with weight status in UK children? $\mathrm{Br} J$ Nutr 115, 1616-1622.

70. Kant AK \& Graubard BI (2015) Within-person comparison of eating behaviors, time of eating, and dietary intake on days with and without breakfast: NHANES 2005-2010. Am J Clin Nutr 102, 661-670.

71. Gorgulho BM, Pot GK, Sarti FM, et al. (2016) Indices for the assessment of nutritional quality of meals: a systematic review. Br J Nutr 115, 2017-2024.

72. Brown AW, Brown MMB \& Allison DB (2013) Belief beyond the evidence: using the proposed effect of breakfast on obesity to show 2 practices that distort scientific evidence. $A m J$ Clin Nutr 98, 1298-1308. 